\title{
A xylarium for the sustainable management of biodiversity: the wood collection of the Royal Museum for Central Africa, Tervuren, Belgium
}

Hans Beeckman

\section{(2) OpenEdition}

\section{Journals}

Édition électronique

URL : http://journals.openedition.org/apad/3613

DOI : 10.4000/apad.3613

ISSN : 1950-6929

Éditeur

LIT Verlag

Édition imprimée

Date de publication : 2 décembre 2003

Référence électronique

Hans Beeckman, «A xylarium for the sustainable management of biodiversity: the wood collection of the Royal Museum for Central Africa, Tervuren, Belgium », Bulletin de l'APAD [En ligne], 26 | 2003, mis en ligne le 16 juin 2008, consulté le 15 septembre 2020. URL : http://journals.openedition.org/apad/3613

Ce document a été généré automatiquement le 15 septembre 2020.

Bulletin de l'APAD 


\title{
A xylarium for the sustainable management of biodiversity: the wood collection of the Royal Museum for Central Africa, Tervuren, Belgium
}

\author{
Hans Beeckman
}

Introduction: wood and the Neolithic revolution

1 Some scientific disciplines base their methodology on the analysis of documents. Others obtain their raw data mainly through experiments and observations, both in the laboratory and in the field. The study material for a third category of disciplines is being kept in big scientific collections. As such, collections exist with animal specimens for zoological research, mineral and stone collections for geology and herbaria for botany. Herbaria traditionally are composed of leaves, flowers and fruits of plant specimens. Lesser known botanical collections are those with wood samples from lignified plants. These collections are called "xylaria" (singular "xylarium", in French mostly called "xylothèque"). They have a reason to exist on their own, possibly apart from herbaria, mainly because the importance of wood in the living nature and in the material culture can not be overestimated.

Indeed, trees and shrubs are dominant plant forms in most of the terrestrial biomass. The appearance of nearly all the natural landscapes from the equator to the poles is dominated by woody plants, except when the climate is extremely harsh, either very cold or very dry. Nowadays almost $30 \%$ of the land is still covered by forests. This is not less than 3869455000 ha. On top of these forests there are a lot of open woodlands and deforested areas where trees continue to play an important role, e.g. the agro forestry systems. Since trees are also the tallest and most massive organisms on earth and since they consist mainly of lignified secondary tissues, it can easily be accepted, even without sophisticated modelling and calculations that they form the greatest part of 
the terrestrial biomass. Therefore, forests, trees and wood should be important topics on forums that discuss biodiversity. This might sound strange, especially in a northern industrialised context where biodiversity is implicitly being understood as synonym with amount of species in a given area. This viewpoint is interested in the abstract entities of biological systematics. It is clear that the concept of biodiversity defined by the Convention on Biological Diversity includes as well the concrete biotic systems (organisms, populations, landscapes, ecosystems and biomes). Both viewpoints, the abstract and the concrete, are necessary to be taken into account by biodiversity preservation campaigns. Indeed, when only the presence of species is stressed, there is a serious risk to dramatically underestimate certain components of biodiversity that play a crucial role in the structure and functioning of an ecosystem. To illustrate that, an example of a giant tree in a tropical rainforest could be given. After several centuries of growth some trees are more than $70 \mathrm{~m}$ high and represent an enormous amount of biomass and as such dominate a quite large ecosystem where many thousands of organisms live. When only the presence of the species is stressed, no difference is being made between this forest giant and a one year old seedling of the same species that is only $5 \mathrm{~cm}$ high and that plays in quantitative and qualitative terms almost no role of some importance in the forest community. Moreover there is a very high probability that it will die very soon.

3 Wood is not only omnipresent in the living nature: but by far most of the material culture is completely or partly made out of it. The first hand tools were probably wooden sticks. During the complete course of history of man, wood has always been indispensable for construction purposes and still it is. Moreover, most of the furniture is made out of wood, even in our industrial era, and one should not forget that paper has also been born in the forest. Wood is highly appreciated not only because the numerous technical applications offered by the great choice of wood species, but also for its aesthetic appeal. Wood is part of our life, and particularly the comfortable environment created by a multitude of grains and colours, will remain a deep-felt and even increasing necessity to the people of the $21^{\text {st }}$ century.

4 For a better understanding of the important position of wood it is appealing to refer to the very first roots of the word "culture". These roots reveal in words as coulter (English), culter and cultri (Latin), kouter ${ }^{1}$ (Dutch), coutre de charrue (French). They are all linked to the ploughing activity. Obviously, ploughing is only possible on treeless land: to allow farming, trees had definitely to be cut. This happened systematically since what can probably be considered as the biggest revolution Homo sapiens sapiens ever experienced: the agricultural revolution in the Neolithic era. The first meaning of "culture" goes back to a revolutionary attitude that mankind better could consume food that he grows himself than he has to collect it from the wild nature, most frequently the surrounding forest. This very first meaning of culture had later been extended to all farming activities (agriculture) and even to all practices where natural products are being grown for human consumption: horticulture, pisciculture, silviculture, apiculture...

5 The experience that agriculture is only possible when the forest is being cleared, gave rise to the phrase that culture started by cutting the first tree. Trees needed not only to be cut to obtain space for agriculture, but "cutting of trees" was also necessary to produce a series of tools. As a metaphor for these tools, again the plough might be considered. Many ploughs in developing countries are still in wood (they have the 
advantage that they are much lighter to carry to the field). Even when the ploughs are not from wood, it should not be forgotten that energy is needed to produce metal ploughs and that, without any doubt, firewood was used to produce heat for melting the iron ore. Next to ploughs there is a very wide spectrum of objects, in agriculture and in what actually is called the whole material culture, that are all made out of wood: not less than 10.000 applications in wood have been reported.

However, the phrase that culture starts by cutting the first tree has unfortunately to be completed by a second one: culture ends by cutting the last one. There is a real danger that a landscape without trees looses its fertile topsoil and turns into a desert where hardly any culture, in all the meanings of the word, is possible anymore. Absence of trees means lack of protection against the forces of nature, be it rainfall, sunlight, wind or cold temperatures. Besides, it should not be forgotten that absence of trees equals as well strongly reduced possibilities to produce artefacts that help to survive the hostile natural environment.

7 Between the extremes of a wilderness that is hostile to mankind and a treeless world, culture appears under many different forms: fine arts, sciences and technology, including agriculture, silviculture and technology.

The definition of a forest management that assures the sustainable production of services and goods and does not lead to the depletion of resources and lack of soil protection is a rather complex topic. To draw the line between good management and ruthless exploitation scientific information is needed. This information is twofold: knowledge is necessary on the forest ecosystem and on the products that are extracted from the forest. Indeed first of all, an ecological approach is needed to evaluate the carrying capacity of a forest ecosystem. A question to be answered for instance is how much timber could be extracted from a forest without holding back the ecosystem functions. Further on, a study of the products extracted from the forest should support a justified use of these. Since wood is by far the most important natural resource from the forest, it is in the science of wood technology that should enhance a better use of the forest products. Joinery for instance is a very demanding application of wood. Window frames should be as well durable to resist mushroom attacks, strong to hold the window glass and stable to remain wind and water proof. Among the many hundreds of timber species, there is only a relatively small selection that assures joinery performance. The science of wood technology should certify wood quality and as such prevent material losses when the wrong timber is being used.

Wood science and in particular the analysis of xylarium samples can contribute to the assembly of information that should underpin management plans aiming at a sustainable production of goods and services. This can be done through research both of an ecological and of a technological nature. Indeed xylaria or wood collections permit information gathering on both the material characteristics and the carrying capacity of the forest ecosystem.

Wood collections

10 Many scientific reference collections have been established with wood samples that are possibly accompanied by derivative collections (three perpendicular thin sections and a set of micro-photographs). The specimens should preferentially be botanically identified by certified herbarium material that consists of leaves, twigs, flowers and fruits. It is of utmost importance to keep in mind at all stages of research and processing, that wood is a biological material and as such characterized by variability. 
To address this variability repetition samples are necessary. Therefore a wood collection needs many specimens of each species, or more generally of each taxon.

The xylarium of Tervuren has been established by the end of the 19e century. The objectives at the beginning were clearly to convince the Belgian public and the economical sector of the use of having a colony in Central Africa. Among the economic products that had been shown at this time were samples of precious Congolese timber species (African Padouk (Pterocarpus soyauxii), African Mahogany (Khaya spp.), Bilinga (Nauclea diderrichii), Iroko (Milicia excelsa)), all collected in the Mayombe forest in West Congo. Later the collection was extended with commercial timbers from all over tropical Africa. Since there is only one big governemental wood collection in Belgium, from the fifties of last century onwards also samples from other continents have been added to the xylarium of the Royal Museum for Central Africa in Tervuren. The focus up till then was clearly on commercial timber species. The collecting policy in the sixties switched and samples form all lignified plant specimens were added: also shrubs and vines were of interest. Since the xylarium should be for scientific reference, it is very important that the specimens could be studied microscopically. Hence it needs to be completed with so called derivative collections that consist of thin microtomic sections and microscopic images of the wood anatomical features.

The format of the samples is variable. Some samples show standardized dimensions, others are stem fragments of reduced size (shrub and vine specimens), some specimens have been sampled by taking stem disks that should permit a detailed tree growth analysis. The database of the xylarium can be consulted online and is continuously being updated $^{2}$.

Wood research to evaluate the carrying capacity of ecosystemsDecoding the memory of trees

13 Contrary to animals trees are stationary and show an open growth. They continue to form new cells, tissues and organs till they die. Every year a new layer of wood is being laid down, as well in stems, branches and roots. A 3500 year old mammoth tree (Sequoiadendron giganteum) can attain a diameter of not less than $12 \mathrm{~m}$. Diameter increment is the result of cell division and cell enlargement in the cambial zone. The cambium is a very special meristematic tissue, just underneath the bark that remains active till the dieback of the plant. Wood (a botanical term for wood is secondary xylem) is being formed from the cambium towards the centre. In the opposite direction it is the inner bark that is laid down (also called the liber or the phloem) but is much less important in quantitative terms. Through the xylem water is being transported from the roots to the leaves. Other xylem functions are mechanical support of the organism and a series of biochemical processes that are related to energy storage, for instance during the cold or dry season, and heartwood formation. Products of the photosynthesis in the leaves are conducted from the leaves downwards through the phloem. These principal structures can be observed on the transverse surface of a cut branch or a tree stump (the end-grain surface). In the centre is the pith, originally the soft middle part of the young shoot. The greater part of the transverse section is the wood or secondary xylem with de succeeding growth rings from old (near the pith) to young (underneath the cambium). Outside the wood are the inner bark or secondary phloem and the outer bark which consists of dead corky tissue. The vascular cambium lies in between xylem and phloem and can only be seen by a microscope. 

periods of high activity. Even when there is no complete dormancy, as it is the case in some tropical regions, the cambial activity shows a certain oscillation when plotted on a time axis. As a result of this dynamic behaviour a pattern of growth rings can often be seen on a transverse section. The number of cells and their expansion determine the width of the xylem layer that is formed during a growing season. A prosperous season results generally in a wide ring, a season characterized by stressful conditions gives a small ring. 5000 years (cf. Bristlecone pines (Pinus aristata) in South Western USA). Information on these factors is being stored in the lignified tissues of the trees, e.g. their tree ring pattern. Signals of the environment are intercepted by some organs (e.g. the leaves or the roots) and transmitted to other tissues like the cambium which react on these stimuli. Because the cambial activity is a function of the environment, the patterns of tree rings reflect the changing environment during the whole life of a tree. Microscopic observations of the tree ring profile allow the decoding of the memory of trees. A rather easy feature to observe and to measure is the tree ring width. This gives a general indication of the complete growing season. Other features give higher resolution information. These features include the tissue level of integration (for instance the latewood density gives information on summer temperatures), the cell level (the size of vessels expresses the water use efficiency) and the chemical level (e.g. the stable isotopes). evident, for instance for farmers. Also wine experts understand quite easily the association between quantity and quality of wine and the weather during the growing season. The observations of the farmer and the wine expert could be extended to the width of the growth rings of the same season. Indeed this could be considered as a theme for dendrochronology, the scientific discipline studying growth ring series. The correlation between the historical information of wine production and tree ring chronologies has been investigated. A dendrochronologist succeeded in finding falsified agricultural production data while studying tree ring patterns in the neighbourhood of state farms: good harvests could be expected in regions when large tree rings are being formed and the reverse.

However, the relationship between climate and tree ring width is most often not easy to establish and relies on a formal statistical approach.

18 The best known application of dendrochronology is probably in the field of art history where objects from material culture could be dated by comparing their tree ring patterns with reference chronologies. Nevertheless there is a wide interest for the information in tree ring series, especially by disciplines involved in diagnosis and evaluation of the vitality of ecosystems, included the global one. Past climates could be reconstructed by tree ring research to underpin climatologic studies. Forest dynamics can be studied and support the establishment of forest management plans aiming at sustainability.

19 The stem disk collections of the Tervuren xylarium provided the study material for several projects aiming at an ecological evaluation of the ecosystem health. In 2004 two $\mathrm{PhD}$ projects have been completed. A first study concerned a contribution to the global 
climatic changes, more precisely the El Nino effect in the Zambesian region ${ }^{3}$, the second the growth patterns of mangrove trees in Kenya ${ }^{4}$.

The ENSO (El Niño Southern Oscillation) signal in tree growth patterns in Miombo

(Trouet, 2004)

Poor infrastructure and low socio-economic development in major parts of southern Africa render the region vulnerable to climate anomalies and extreme weather events. Due to this high vulnerability, climate change and low-frequency climatic phenomena as the El Niño Southern Oscillation (ENSO) can lead to extreme negative impacts on societies. Long-term research of interannual climate variability would allow the prediction of future climatic events and the development of early warning systems. Instrumental climate records in southern Africa are very limited in temporal and spatial coverage, but proxy climatic data offer a potential solution. Tree ring data can contribute to the proxy data record. This study involves analyzing the dendroclimatological possibilities (mainly concerning the El Nino signal) of trees in the region of the Miombo woodland in southern Africa. Growth analysis and remote sensing are used to estimate the net primary production of vegetation. Growth curves are also established to draw up plans for the sustainable management of the forest of Miombo.

21 Stem disks have been analyzed of six species from fourteen sites throughout the Miombo region in south-central Africa. It appeared that all species form distinctive growth rings, characterized by terminal parenchyma bands. Successful cross dating was possible at all sites which is an indication of a common external driving force for cambial growth. At all sites water availability is most probably the limiting factor to radial growth. Influence of climate and rainfall in particular, on tree growth appeared to be strongest at the core of the rainy season, when precipitation rates are highest. The ENSO-effect on rainfall variability in southern Africa is strongest during the same time-period. During the warm El Niño phase, rainfall is generally lower than normal in southern Africa, leading to a decrease in tree growth. In the subsequent La Niña phase, enhanced rainfall and some tree growth anomalies occur. The tree-ring chronologies developed in this study reach back to 1853 , but a 30 year moving average correlation analysis has shown that correlation to ENSO is strongest from 1970 onwards. This period coincides with an enhanced relation between ENSO and rainfall and an increasing magnitude of interannual rainfall variability in southern Africa. It has been shown that a dendrochronological network could be build for the Miombo region in southern Africa.

Driving variables for the cambial activity of mangrove trees (Verheyden, 2004)

Worldwide mangrove deterioration has been attributed to anthropogenically or climatologically induced alterations in environmental conditions. However, due to the lack of long-term datasets, causal relationships are hard to prove. Certain mangrove trees exhibit rings on transversal cross-sections. These tree rings are not distinct in anatomical terms. The growth rings are composed of a low vessel density earlywood, produced during the long and short rain season and a high vessel density latewood, produced during the dry season. The growth ring boundary is indistinct and is characterized by a gradual change in vessel density. The annual growth rings provide information on the age and the growth rate of trees. However, ring width time-series failed to synchronize, indicating that the interannual variability in tree growth cannot be used as a proxy to study changes in environmental conditions on a annual 
resolution. Therefore, the more detailed environmental information stored in the wood anatomy, stable carbon and oxygen isotope ratios and the inorganic composition of the tree rings was investigated. Inter-annual variability in vessel density and size revealed a trade-off between hydraulic efficiency (large vessels) during the rain season and hydraulic safety (small, more numerous vessels) during the dry season. In addition to this annual earlywood/latewood signal, a semi-annual signal was also discovered after a numerical Fourier transformation of the high-resolution vessel density and diameter profiles. The annual and semi-annual signal was also observed in the Fourier spectra of the precipitation and relative humidity and is related to the bimodal distribution of the rainfall in Kenya, resulting in a long and short rain season (semi-annual signal) and one distinct dry season (annual signal). The similarity in the Fourier spectra of the climate data and the vessel features offers strong additional evidence for a climatic driving force controlling the vessel density and diameters, either through changes in the relative humidity or through changes in the pore water salinity caused by precipitation, or both. High resolution stable isotope profiles revealed a clear annual cyclicity with minima and maxima occurring in the vicinity of the latewood/earlywood and earlywood/latewood boundaries, respectively. The presence of this annual cyclicity offers a high potential for identifying growth rings in tropical trees that lack visible anatomical growth rings. In addition, the presence of a conspicuous pattern in the isotope signal in the El-Niño year 1997, in all the trees analyzed indicates that years with extreme climatic events ("event years") are archived in the wood and can possibly be used for cross dating the tree rings. Similarity between the high-resolution isotope profiles of the mangrove trees and temperate tree species suggests that the annual cyclicity is the result of a climatic signal superimposed on the signal caused by postphotosynthetic processes. This study demonstrates the potential of Rhizophora mucronata as an environmental proxy. The techniques developed during the project offer potential to the field of dendrochronology as a whole and the estimation of tropical forest production in particular.

The study of the material for a better use

Wood anatomy is a study of tissues and cells, the biotic fundaments of wood

Wood is from living beings. It is therefore characterized by two fundamental features. First it is highly compartmentalized: it consists of cells, the smallest autonomous units of life. Secondly, like all biodiversity items and unlike man-made products, wood shows an extraordinary variability: features may be very different not only between two species, but also from one individual to another, or even from one sample to another. The outer wood at the bark side of old grown trees has for instance very different qualities than the wood around the pith that is formed by the young cambium. Wood cannot be understood as artificial products as steel, concrete or glass. It needs a biological approach. Many problems in construction have their roots in neglecting the biological nature of wood, for instance during the education of engineers and architects.

Awareness of both fundamental features is absolutely necessary to understand the material wood and also to identify it: wood identification is based on the observation of cells and tissues, but it is always important to put the observations in a context of variability and diversity. Questions always to be asked are "Is the studied sample representative?", "How far is the reference collection complete to address a particular identification problem?" 

woods.

Wood is anisotropic
The fundamental reason why wood identification through microscopic study is important is the principle belief that plant systematics is an interesting organisation of information, including of wood technological features. The taxon provides information on features. This is extremely relevant for a management that aims at a sustainable use of forests and forest products. In recent years wood identification becomes very important in the context of the Washington convention on endangered species (CITES). Some commercial timbers have been added to the appendices of the convention texts, which means that custom and police services have to be trained in wood observation to strengthen their performance during control of international trade.

Wood is heterogeneous

The different cell types that compose wood make it to a very heterogeneous material. The typical arrangement of the cells characterizes the botanical taxon which could be the species, the genus or an even larger entity. Three main tissue types exist. First there is the conductive tissue to transport water from the soil to the leaves. Secondly, a support tissue assures the strength of trees and timber. At last there is the parenchyma tissue that is liable to a series of biochemical processes like heartwood formation and storing of reserve substance (starch). The conductive tissue of hardwoods (angiosperms) consists mainly of vessels or pores: big perforated cells that are placed one above the other to form tube like structures. Their support tissue consists predominantly of fibres: long cells with a small diameter and thick cell walls. Softwoods (conifers, gymnosperms) have cells that combine the functions of conduction and support: the tracheids. In both hardwoods and softwoods there are two types of parenchyma tissue: axial parenchyma and radial parenchyma. The latter forms the wood rays. For the visual aspects of angiosperm timber, there are two important wood anatomical features: porosity and type of axial parenchyma. The porosity is especially important for temperate woods, while axial parenchyma matters more in tropical

Cells and tissues and the way that they are arranged characterize the wood physical, mechanical and visual features. Knowing these features is crucial for a sustainable use of wood to make sure that the right material is chosen for the right application.

Wood is not only heterogeneous; it shows also a very distinct anisotropy: cells and tissues are arranged either in the radial or in the longitudinal direction. The scientific approach of wood anatomy studies the three-dimensional structure by establishing a system of three particular microscopic images. This derivative collection of images is necessary to validate the scientific nature of the collection.

The first image is obtained by viewing a plane that cuts perpendicularly through the longitudinal axis of the tree stem or branch. This is called the transversal section. The section is particularly useful to judge the vessel arrangement, the growth ring border, the axial parenchyma pattern and at a larger magnification the cell wall thickness

The second section is the tangential section and is acquired by a plane that is parallel to the main axis but doesn't cut through this axis: it is tangentially to the growth rings. This section is used in the first place to observe the rays. They appear on a tangential section as fusiform shapes

the wood rays from the pith to the bark. This section is needed to evaluate for instance 
the composition of the rays. Both longitudinal sections are used to watch a series of fine and ultra fine structures, like there are the pits that connect different cells. They are all of relevance for identification purposes.

The three sections could microscopically be observed with incident and transmitted light or with electronic bundles. Some of the features could be seen with a hand lens or even with the naked eye. Magnifications up to 6000x may be needed (only possible with electron microscopes), but for most of the cases optic microscopes with a maximum magnification of 400 times are sufficient.

Growth ring delimitations

From wood anatomical observations it is clear that growth ring borders could be marked by different kinds of tissues. Most frequently following wood anatomical changes permit to define ring borders. Many growth ring borders are distinct because there is an abrupt transition from thick walled late wood fibres or tracheids (formed at the end of the growing season) to thin walled early wood fibres or tracheids (formed in spring or beginning of the summer). Such a discontinuity is obvious for most of the conifers. For some deciduous species or hardwoods there is a clear difference between latewood of the previous ring and early wood of the next ring, like it is the case for ring porous and semi-ring porous species (oak - Quercus spp., ash - Fraxinus spp, teak - Tectona grandis,...). Some species, especially in the tropics, show a layer of marginal parenchyma, which could either be terminal or initial: a small parenchyma band of a few cells wide that is arranged in concentric circles (merbau - Intsia bijuga, afzelia - Afzelia spp.,...).

The identification process

The identification process of a wood sample from unknown origin involves three steps.

In a first step the material is prepared for observation. A first question deals unavoidably with the location of the wood in the original tree. A sound orientation is of uttermost importance. Therefore it is in most of the cases necessary to start with a macroscopic observation of a clean transverse surface. Most easily this is being obtained by clean cutting a small surface with a sharp knife. Observations of ring borders and wood rays are sufficient for an orientation. Most frequently this is being done with a hand lens with a magnification factor of 10 times. After this first inspection, the thin sections could be made. This could be done either by a microtome, a scalpel or a razor blade. The former is especially interesting for reference samples that need to be of high quality and that should be kept for a very long time. Microtome sectioning is accompanied by a series of material processing steps like there are softening, dehydrating, staining and imbedding in resin. These handlings need to be done in a specialised laboratory. For sections that don't need to be stored for a long time and where the quality is less important, hand sections could be made with a scalpel. When thin sections are difficult to realize small pieces of solid wood can be analysed by incident light microscopy.

37 A second step involves the observation of the features. An attempt to standardize the wood anatomical observation for identification purposes is made by the International Association of Wood Anatomists (IAWA). They elaborated a list of not less than 163 different descriptors to analyse a wood specimen. Most formally a wood anatomical observation involves scoring the standardized IAWA characters on a checklist. 
38 A third step involves comparing the observations with those of scientific reference collections, possibly using published identification keys, picture atlases or tables with listed characters.

Experienced wood anatomists often don't work formally, but dynamically combine literature, software and human expertise.

Identification of precious objects

The procedure of wood identification of precious objects including art historical and ethnographic items does not differ from the identification of objects without much value. It is of course seriously hampered by the possibilities to make the necessary observations. However in by far most of the cases very small fragments could be taken. This sampling is hardly noticeable and is absolutely not destructive for the objects. In some cases it is preferred that the sampling is being done by recognized art restorers. Because the wood anatomical observation needs high resolution information from different magnification levels, there are no operational automatic tomographical techniques that replace the standard technique of sectioning. The resolution of a medical scanner for instance does not allow observations on a cellular or sub cellular level. It is important to keep in mind that most of the wood collections are far from being complete not only because some wood species are lacking, but also because they don't cover the complete picture of the natural variability of certain woods.

The macroscopic study of grain, texture and colour

41 Next to the microscopic characteristics of the material, there is a series of macroscopic features that also determine a part of the technological behaviour and the esthetical aspects of the wood. They are generally of less importance as is comes to identification, but could complete the microscopic observations.

The way that wood is being formed gives rise to a radial symmetry in the wood structure. This can be seen very easily on a transversal section. A stem or a log being cut longitudinally shows a changing appearance of the wood with the position of the cut. If the saw cut passes exactly through the pith a perfect radial section is obtained. The timber, obtained by saw cutting in a radial direction, is called quartered sawn or silver grain timber. The ring borders viewed on the transversal section are at right angles with the flat side of the timber. Flat sawed timber is being converted so that the growth layers meet the face of any part at an angle less than 45 degrees. Bastard sawed timber shows parts where the growth rings form as well angles of less than 45 degrees and more than 45 degrees.

43 The grain of the wood is determined by the main direction of cells and tissues: the way that wood elements are arranged according to the length axis of the tree. The grain is being observed on the longitudinal surfaces. If the axial elements are all aligned parallel to the length of the stem or the piece of timber, the grain is straight. Many irregularities could cause deviations. The presence of knots for instance gives rise to diversion of the nearby axial elements.

Very often old trees show the so called spiral grain where the elements are laid down along helical paths around the main axis. The mechanical explanation for this phenomenon is probably related to rigidity. Like a rope is more rigid than the sum of the constituent threads, resists a tree with spiral grain better to wind forces than trees without spiral grain. Spiral grain has a genetic foundation, but is more expressed in trees that are subjected to strong winds like free standing trees. It is one of the reasons 
why trees out of a dense forest are much more valuable from a technological viewpoint than street trees or trees from a wide spaced plantation. Planks from trees showing spiral grain don't have much form stability: they warp during the drying process. Spiral grain can sometimes be seen on the fissuring pattern of the bark. Nevertheless it should be remembered that the bark is not always a very reliable indicator of the grain because it is not necessarily related to the growth history. A young oak tree may show a spiral grain with left direction (S-spiral), while old oaks have right directed spiral grain. The bark pattern only suggests right-hand (Z-spiral) grain.

In some woods, especially in tropical ones, the direction of the spiral changes regularly with a rhythm of some years: this is called the interlocked or double grain. This could be seen the easiest on a radial surface. Sometimes regularly repetitive deviations of the straight axial direction occur so that the grain follows a sinuous course which can be observed on the tangential surface: the wood has a undulating or wavy grain. The wavelength is usually of the order of a few millimetres. When the deviations of the straight grain are less regular the term twisted grain is being used.

The texture indicates whether the wood is constituted by large or small elements. Very important is the size of the vessels, as far as deciduous woods are concerned. Also the diameter of the fibres and the growth ring width determine the texture. Diffuse-porous woods with vessels of moderate sizes are even-textured. When the vessels are small the wood is said to be fine-textured. Ring-porous trees with large vessels or pores in the early wood and dense tissues in the latewood have a course or uneven texture.

Slow grown oak with no or much reduced latewood is thus more even-textured than fast-grown timber. It is also less dense and is often preferred by cabinet makers and wood carvers, because is can more easily be processed.

The colour of the wood is often related to the process of heartwood formation. As the trunk increases in diameter the older wood, nearer the centre, stops its physiological functions. The living cells die, the moisture content often decreases and sometimes dark-coloured substances are being deposited. This is the heartwood that is different from the sapwood.

Except for blue all colours could be found among the woods of the world. The natural colour of the wood of a certain tree species could be very variable, not only between several specimens of the same species, but even within one stem. Wood colour is also subjected to alterations: it changes rapidly just after felling or sawing and during the drying process, because of changing moisture content. The colour of the end products changes rather slowly with time, because of light and oxidation effects. Dark woods generally become lighter and light woods become darker. Because of the variability identification and description should not focus too much on colours.

The bridging function of wood

The aims of wood research and xylarium collecting policies have in the past predominantly been oriented by industrial purposes. This is a rather limited scope, sometimes with awful consequences. In the first place the amount of wood species is reduced to only a few timbers that are considered to be of interest for the world market and by far the biggest amount of lignified plant species remains scientifically unexplored. When focus is only on a few timbers that are relatively well known for industrial applications, strong forces arise that tend to make the forests more homogeneous and uniform. This reduces as per definition the biodiversity of these ecosystems. Another problem is that an industrial attitude neglects the very biological 
nature of the wood. This leads often to a misuse of the precious material. On the long run there is a risk that artificial and ecologically much less sound products like PVC, steel or aluminium replace the natural renewable substance that is wood.

When, at the contrary, scientific wood collections incorporate as many woody plants as possible the gateways are being opened for many research disciplines that all show interest in wood and contribute to the sustainable use of the world forest ecosystems and this of the most important material that they produce. These disciplines include next to technology, forestry, tree physiology and ecology, also archaeology, palaeontology, ethnography and art history. Hence, wood is bridging easily the gap between natural and human sciences, probably towards the only scientific way to a sustainable and sound use of the ecosystems that compose the world where we live in.

\section{NOTES}

1. The Dutch word "kouter" refers to the vertical knife in front of the plough that cuts the soil. In extension it is sometimes used for the plough as a whole. The southern Dutch "kouter" is also used for a field of arable land that is being ploughed regularly. The origin of these "kouters" can be situated between the 6th and the 9th centuries where the best soils were selected for cultivation.

2. http://www.metafro.be/xylarium/wood_collection

3. Trouet, V. (2004). The El Niño Southern Oscillation effect on Zambesian miombo vegetation: proxies from tree ring series and satellite-derived data. Dissertationes de Agricultura. Doctoraatsproefschrift nr. 638 aan de faculteit Bioingenieurswetenschappen van de K.U.Leuven.

4. Verheyden, A. (2004) Rhizophora mucronata wood as a proxy for changes in environmental conditions. A study of the wood anatomy, stable isotope chemistry and inorganic composition of a Kenyan mangrove species. Proefschrift voorgedragen tot het behalen van de graad van doctor in de Wetenschappen. Vrije Universiteit Brussel.

\section{AUTEUR}

\section{HANS BEECKMAN}

Laboratory for Wood Biology and Xylarium-Royal Museum for Central Africa, Tervuren, Belgique 